\title{
Predictive Accuracy of the
}

\section{Post-stroke Depression Prediction Scale}

(Depres)

Julian Hirt 1, Lianne van Meijeren 2, Gabriele Meyer ${ }^{1}$, Susanne Saal ${ }^{1}$, Janneke M. de Man-van Ginkel ${ }^{2}$

${ }_{1}^{1}$ Institute for Health and Nursing Science, Medical Faculty, Martin Luther University Halle-Wittenberg, Halle (Saale), Germany

2 Julius Center for Health Sciences and Primary Care, Nursing Science, University Medical Center Utrecht, University Utrecht, Utrecht, The Netherlands

\section{Background}

Almost every third stroke patient suffered from depression after stroke [1]. The early assessment of depression in patients after stroke is essential for optimizing recovery.

To support the early identification, given the limited mean hospital stay of stroke patient of less than 2 weeks, the Post-stroke Depression Prediction Scale (DePreS) has been developed to estimate in the first week after stroke the risk of depression in the second month after stroke [2].

\section{Objective}

To establish in a new sample of hospitalized stroke patients the predictive accuracy of the DePreS.

Methods:

A cross-sectional study in a consecutive sample of 93 stroke patients able to communicate adequately admitted to one hospital in the Netherlands and two hospitals in Germany.

\section{Data collection:}

The DePreS has been translated into German according the ISPOR criteria [3].

Index test (within the first week after stroke):

- DePres [2]

Reference test (six to eight weeks after stroke):

- CIDI $[4,5]$

Researchers conducting the reference test were blinded for the results of the index test.
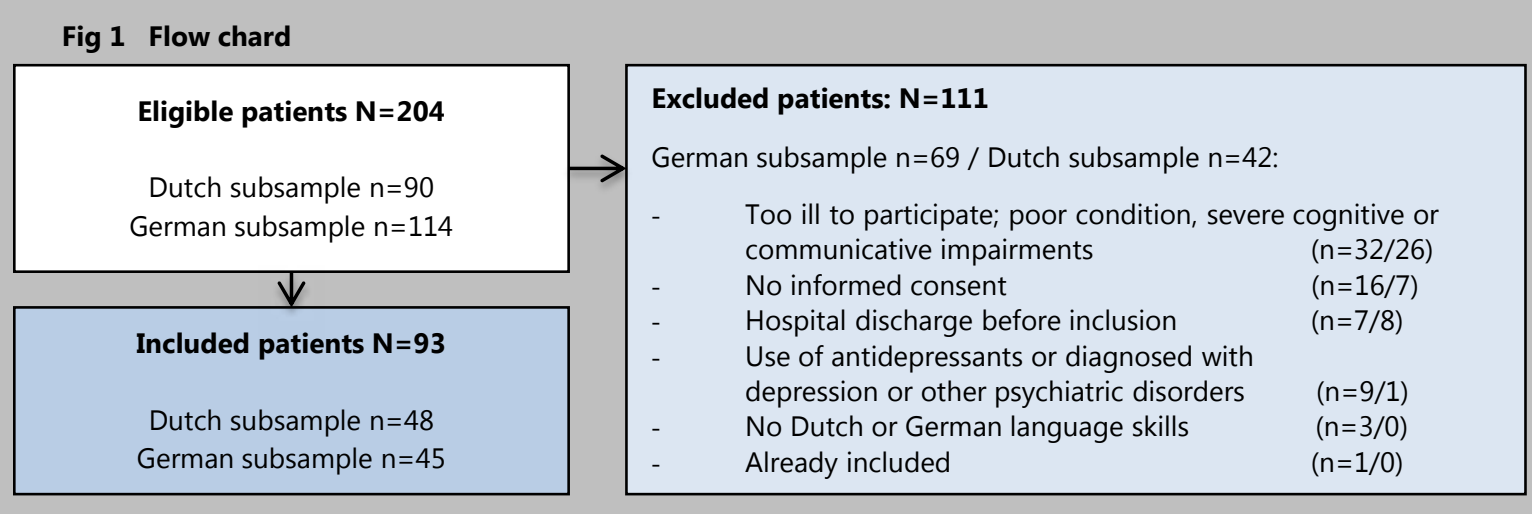

\section{Table 2: Performance of the DePreS}

\begin{tabular}{cccccc}
\hline Cut-off & $\begin{array}{c}\text { Sensitivity } \\
(95 \% \mathrm{CI})\end{array}$ & $\begin{array}{c}\text { Specificity } \\
(95 \% \mathrm{CI})\end{array}$ & $\begin{array}{c}\text { Positive } \\
\text { predictive value } \\
(\mathrm{PPV})(95 \% \mathrm{CI})\end{array}$ & $\begin{array}{c}\text { Negative } \\
\text { predictive value } \\
(\mathrm{NPV})(95 \% \mathrm{CI})\end{array}$ & Youden's index \\
\hline-5 & $0.82(0.64-1.00)$ & $0.33(0.22-0.43)$ & $0.22(0.12-0.32)$ & $0.89(0.82-0.97)$ & 0.15 \\
-2 & $0.71(0.49-0.92)$ & $0.66(0.55-0.76)$ & $0.32(0.17-0.46)$ & $0.91(0.82-1.00)$ & 0.37 \\
0 & $0.65(0.42-0.87)$ & $0.74(0.64-0.84)$ & $0.35(0.19-0.52)$ & $0.90(0.80-1.00)$ & 0.39 \\
2 & $0.41(0.18-0.65)$ & $0.88(0.81-0.95)$ & $0.44(0.19-0.68)$ & $0.87(0.71-1.03)$ & 0.29 \\
3 & $0.35(0.13-0.58)$ & $0.93(0.88-0.99)$ & $0.55(0.25-0.84)$ & $0.87(0.66-1.07)$ & 0.28
\end{tabular}

AUC: 0.71 (95\% Cl: 0.56-0.86)

\begin{tabular}{|c|c|c|}
\hline & $\begin{array}{l}\text { Netherlands } \\
\mathrm{n}=48(52 \%)\end{array}$ & $\begin{array}{r}\text { Germany } \\
n=45(48 \%)\end{array}$ \\
\hline \multicolumn{3}{|l|}{ Sex, n (\%) } \\
\hline Male & $30(62.5)$ & $27(60)$ \\
\hline Age, Mean (SD; min-max) & $74(11.8 ; 44-93)$ & $66.7(13 ; 44-91)$ \\
\hline \multicolumn{3}{|l|}{ Type of stroke, $n(\%)$} \\
\hline Intracerebral heamorrhage & 0 & $2(4.4)$ \\
\hline Ischaemic infarction & $48(100)$ & $43(95.6)$ \\
\hline \multicolumn{3}{|l|}{ Symptoms, n (\%) } \\
\hline Motor & $36(75)$ & $19(42.2)$ \\
\hline Sensory & $12(25)$ & $16(35.6)$ \\
\hline Speech & 19 (39.6) & $14(31.1)$ \\
\hline Language & $3(6.3)$ & $4(8.9)$ \\
\hline Visual & $13(27.1)$ & $12(26.7)$ \\
\hline \multicolumn{3}{|l|}{ Vascular risk factors, $\mathrm{n}(\%)$} \\
\hline Diabetes mellitus & $10(20.8)$ & $18(40)$ \\
\hline Hypertension & $31(64.6)$ & $33(73.3)$ \\
\hline Dyslipidemia & 19 (39.6) & $17(37.8)$ \\
\hline Smoking & $12(25)$ & $13(28.9)$ \\
\hline Alcohol consumption & $29(60.4)$ & $19(42.2)$ \\
\hline \multicolumn{3}{|l|}{ Discharge direction, $\mathrm{n}(\%)$} \\
\hline Home & $29(60.4)$ & $16(35.6)$ \\
\hline In-hospital Rehabilitation & 19 (39.6) & $27(60)$ \\
\hline Other & 0 & $2(4.4)$ \\
\hline \multicolumn{3}{|l|}{ Barthel Index Mean (SD; min-max) } \\
\hline 1 week post stroke, & $14(5 ; 3-20)$ & $16(5 ; 2-20)$ \\
\hline 6-8 weeks post stroke & $18(4 ; 3-20)$ & $18(3 ; 7-20)$ \\
\hline Major Depressive Disorder (CIDI), n (\%) & $11(20.8)$ & $7(15.6)$ \\
\hline
\end{tabular}

\section{Conclusion}

- The good predictive accuracy of the DePreS is confirmed in a new sample of stroke patients. The AUC in this study is almost equal to the value found in the development study: 0.71 (95\% CI: 0.56-0.86) vs 0.78 (95\% CI: 0.72-0.85).

- The DePreS showed the best performance for the cutoff value of 0 with an acceptable to good specificity combined with an excellent negative predictive value.

- The high specificity and NPV indicate the DePreS being in particular appropriate for the identification of stroke patients who are not at risk of PSD. Hence, by using the DePreS clinicians are able to exclude for further diagnostic and treatment follow-up, patients not at risk for depression in the first week after stroke.

\section{References}

1. Hackett, M. L. \& Pickles, K. (2014). Part I: frequency of depression after stroke: an updated systematic review and meta-analysis of observational studies. International Journal of Stroke, 9 (8), 1017-1025.

2. Man-van Ginkel, J. M. de, Hafsteinsdottir, T. B., Lindeman, E., Ettema, R. G. A., Grobbee, D. E. \& Schuurmans, M. J. (2013). In-hospital risk prediction for post-stroke depression: development and validation of the Post-stroke Depression Prediction Scale. Stroke, 44 (9), 2441-2445.

3. Wild, D., Grove, A., Martin, M., Eremenco, S., McElroy, S., Verjee-Lorenz, A. et al. (2005). Principles of Good Practice for the Translation and Cultural Adaptation Process for Patient-Reported Outcomes (PRO) Measures: report of the ISPOR Task Force for Translation and Cultural Adaptation. Value in Health, 8 (2), 94-104.

4. Ter Smitten R, Smeets R, Van den Brink W. Composite International Diagnostic Interview_Computerized Version 2.1: Dutch Translation and Adaptation: WHO-CIDI Training en Referentie Centrum. Amsterdam, The Netherlands: Psychiatrisch Centum AMC; 2008.

5. World Health Organization (1990). CIDI Manual. Eine Einführung und Durchführungsbeschreibung zum Composite International Diagnostic Interview. Deutsche Bearbeitung: Hans-Ulrich Wittchen. Weinheim: Beltz Test. 